\title{
Autograft or allograft for reconstruction of anterior cruciate ligament: a health economics perspective
}

\author{
Hema Mistry ${ }^{1}\left[\right.$ - Andrew Metcalfe ${ }^{2} \cdot$ Jill Colquitt $^{3} \cdot$ Emma Loveman $^{3} \cdot$ Nick A. Smith $^{4} \cdot$ Pamela Royle $^{1}$. \\ Norman Waugh ${ }^{1}$
}

Received: 5 December 2018 / Accepted: 20 February 2019 / Published online: 14 March 2019

(c) The Author(s) 2019

\begin{abstract}
Purpose To assess the clinical and cost-effectiveness of allografts versus autografts in the reconstruction of anterior cruciate ligaments.

Methods Systematic review of comparative clinical effectiveness and cost-effectiveness analysis.

Results Both autograft and allograft reconstruction are highly effective. Recent studies show little difference in failure rates between autografts and allografts (about $6 \%$ and 7\%, respectively). In cost-effectiveness analysis, the price differential is the main factor, making autografts the first choice. However, there will be situations, particularly in revision ACL reconstruction, where an allograft may be preferred, or may be the only reasonable option available.

Conclusion In ACL reconstruction, clinical results with autografts are as good as or slightly better than with allografts. Allografts cost more, indicating that autografts are more cost-effective and should usually be first choice.

Level of evidence II.
\end{abstract}

\section{Introduction}

Rupture of the anterior cruciate ligament (ACL) is not uncommon in people taking part in sports. A full description of the clinical aspects is provided in another article in this issue, by Hulet et al. [20]. ACL rupture can sometimes be managed conservatively but results are considered better with reconstruction, especially regarding stability, although further trials are ongoing. Non-operative approaches may be considered in lower demand patients but may result in ongoing instability, and are not cost-effective in sportspeople [38], whereas ACL reconstruction gives good results, and allows people to get back to vigorous, and indeed international level, sport. A cost-effectiveness analysis by Stewart

Hema Mistry

hema.mistry@warwick.ac.uk

1 Division of Health Sciences, Warwick Medical School, Gibbet Hill Campus, University of Warwick, Coventry CV4 7AL, UK

2 Warwick Clinical Trials Unit, University of Warwick Medical School, Coventry CV4 7AL, UK

3 Effective Evidence, Waterlooville, Hampshire PO8 9SE, UK

4 Department of Orthopaedics, University Hospitals Coventry and Warwickshire, Coventry CV2 2DX, UK et al. [40] concluded that ACL reconstruction was costeffective compared to physiotherapy and no reconstruction in competitive athletes.

Some people do try to repair the ACL, but results do not so far seem to have been good. This article is only concerned with reconstruction.

Autografts can come from different source tendons. The commonest source now seems to be hamstring tendons but some surgeons prefer bone-patellar tendon-bone (BPTB) as first line, and others use BPTB in high-risk patients.

Allografts come from various sites, including tibialis anterior, quadriceps, Achilles tendon, BPTB and hamstrings (HS).

As noted by Hulet et al. [20], practice varies, with allografts used much more often in some countries than others. Prentice et al. [37] reported practice in six registries, in Denmark, Luxembourg, Norway, the UK, Sweden and the USA, with data from 101,125 procedures (95\% from Scandinavian countries, $4 \%$ from the UK). In Europe, allografts were used in few patients $(0.3-6.3 \%)$, whereas they were used in $40 \%$ in the US centres (Kaiser Permanente). Revision rates by 7 years were reported for Norway $(5.6 \%)$, Sweden $(4.1 \%)$ and $\mathrm{KP}(6.1 \%)$.

The advantages of allografts are no donor site morbidity, a shorter operation and less painful initial recovery. 
The disadvantages are slower graft incorporation and concern about higher rupture rates in some young highly active groups, concern about disease transmission and increased cost. See review by Hulet et al. [20]. The concern about a higher re-rupture rate may not be warranted and may date from the time when allografts were irradiated or chemically cleansed, and weakened by that. Disease transmission is now rare following more rigorous testing of donors.

\section{Materials and methods}

Recent good-quality systematic reviews were identified first, followed by any recent trials not included in those reviews. A high-quality, recent review of both systematic reviews and randomised trials (RCTs) by Zeng et al. [52] was identified comparing allografts and autografts in primary ACL reconstruction. This review was used as the starting point and only primary studies that were published since the dates of its searches in 2014 were included. For completeness, eight other good-quality recent systematic reviews were examined. Wasserstein et al. [45], Kan et al. [21] and Cvetanovich et al. [12] were reviews of primary ACLs. A review by Mascarenhas et al. [29] was a review of meta-analyses. Yao et al. [50] included only studies before 2014 so was not discussed further. Bansal et al. [2] was a good-quality review but specifically on infections. It reported a much higher rate with HS autografts than with BPTB autografts, though this was based on observational studies, but no difference overall between autografts and allografts. Wei et al. [47] compared autografts with nonirradiated allografts. Park et al. [36] also focused on the irradiation issue. This article does not discuss radiation further as it is covered in the review by Hulet et al. [20].

Two reviews by Grassi et al. [17] and Mohan et al. [30] considered revision ACL reconstruction. Grassi et al [17] found that autografts gave better results than allografts in revision ACL reconstruction. Whereas, Mohan et al. [30] found revision ACL reconstruction had failure rates similar to autograft or allograft reconstruction.

Cost-effectiveness analysis A decision tree model in Microsoft Excel ${ }^{\circledR}$ was considered the most appropriate choice as ACL reconstruction is usually successful and most patients return to a functioning knee after reconstructive surgery. The starting point for the economic model is the decision to do an ACL reconstruction; the model does not include a non-reconstruction arm. The clinical pathways were developed using information from the published literature and clinical experience. Further information on the economics model including the structure is provided in the full report on the ESSKA website.

\section{Base-case analysis}

For the base-case analysis, a 3-year time horizon was adopted. The analysis does not differentiate by gender nor mortality is taken into account. The starting age for a patient is 25 years. The analysis is conducted from the perspective of the UK National Health Service (NHS) and personal social services (PSS). All costs are in pounds sterling (£) in 2016/2017 prices. Health outcomes are measured in quality-adjusted life years (QALYs). Results are expressed as incremental cost-effectiveness ratio (ICER) more commonly known as a cost per QALY gained. An annual discount rate of $3.5 \%$ is applied to both costs and outcomes in line with recommended guidelines [31].

\section{Resource use and costs}

All unit costs reported in Table 1 are presented in pounds sterling (£) in $2016 / 17$ prices. The cost of the allograft (£2250) was based on the NHS Tissue Services price list for 2018/19 [32] and was an average of the prices of the tendons likely to be used, such as the tibialis anterior one (which once doubled is the same size or thicker than the combined semitendinosus and gracilis graft). The exact prices are classed as confidential. There is no cost for the graft in the HS autograft arm.

It was assumed that $0.3 \%$ of all reconstructions will get infections based on a recent ACL study by Waterman et al. [46]. The cost of infections was obtained from the Genuario et al. paper [13] in US \$ in 2010 prices. Costs into UK $£$ in 2017 prices were converted using the World Bank gross domestic product (GDP) deflators [48] and the purchasing power parity (PPP) measures [34]. The cost of treatment for an infection included the cost of debridement, irrigation, and antibiotics started intravenously with 1 -week hospital admission then continued for a further 5 weeks [3].

For the base-case analysis, probabilities for the decision model were obtained from the literature and clinical expert opinion (see Table 2). For the 1st ACL reconstruction, these probabilities were obtained from a systematic review and meta-analysis of randomised controlled trials which focused on autograft versus allograft in ACL reconstruction by Zeng et al. [52]. Five trials were included in the forest plot metaanalysis for the subgroup analysis of autograft versus nonirradiated allograft failure (Fig. 1) ([24, 33, 41-43]). There were 16 events in the autograft arm which resulted in a failure rate of $5.57 \%(n=287)$ and there were 20 events in the allograft arm with a failure rate of $6.92 \%(n=289)$.

For the second ACL reconstruction, probabilities were obtained from the paper by Mohan et al. [30], who 
Table 1 Resource use and costs for ACL reconstruction

\begin{tabular}{|c|c|c|}
\hline Resource use & Unit cost $(\mathfrak{f})$ & Source \\
\hline \multicolumn{3}{|l|}{ Graft type } \\
\hline Allograft & $£ 2250$ & [32] \\
\hline \multicolumn{3}{|l|}{ Procedure } \\
\hline Intermediate knee procedures for non-trauma, 19 years and over (HRG code: HN24C) & $£ 1642$ & {$[15]$} \\
\hline \multicolumn{3}{|l|}{ Other related costs } \\
\hline Three consultant led outpatient follow-up attendance (HRG code: WF01A) & $£ 336$ & {$[15]$} \\
\hline 8 hospital physiotherapy sessions (30 min) & $£ 132$ & {$[10]$} \\
\hline Paracetamol (two tablets twice a day per year) & $£ 23.21$ & [5] \\
\hline Ibuprofen (one tablet a day per year) & $£ 12.47$ & {$[5]$} \\
\hline \multicolumn{3}{|l|}{ Total costs } \\
\hline Allograft & $£ 4395$ & \\
\hline HS autograft & $£ 2145$ & \\
\hline BPTB autograft & $£ 2145$ & \\
\hline \multicolumn{3}{|l|}{ Infection } \\
\hline Infections & $£ 7761$ & {$[13]$} \\
\hline \multicolumn{3}{|l|}{ Conservative care } \\
\hline One consultant led outpatient follow-up attendance (HRG code: WF01A) & $£ 112$ & {$[15]$} \\
\hline 8 hospital physiotherapy sessions (30 $\mathrm{min}$ ) & $£ 132$ & {$[11]$} \\
\hline
\end{tabular}

Table 2 Probabilities for ACL reconstruction

\begin{tabular}{lll}
\hline Pathway & Probability & Source \\
\hline Allograft pathway & & \\
1st Allograft & & \\
Success & 0.931 & {$[50,52]$} \\
Fail & 0.069 & \\
2nd or 3rd Allograft & & \\
Success & 0.964 & [30] \\
Fail & 0.036 & \\
HS autograft pathway & & \\
1st HS Autograft & & [52] \\
Success & 0.944 & \\
Fail & 0.056 & \\
2nd or 3rd Allograft & & \\
Success & 0.964 & \\
Fail & 0.036 & \\
2nd or 3rd BPTB Autograft & & \\
Success & 0.959 & \\
Fail & 0.041 & \\
2nd or 3rd HS Autograft (other leg) & & \\
Success & 0.959 & \\
Fail & 0.041 & \\
\hline
\end{tabular}

conducted a random effects meta-analysis of clinical outcomes in revision ACL reconstruction. The primary outcome was graft failure. Eight studies with a combined number of 2302 patients provided an autograft failure rate of $4.1 \%(95 \%$ CI $2.0-6.9 \%)$ and two studies with a combined number of 671 patients provided an allograft failure rate of $3.57 \%$ (95\% CI $1.38-6.74 \%$ ).

\section{Utilities}

For patients who have a successful ACL reconstruction, population norm values provided by Ara and Brazier [1] were used. Genuario et al. [13] reported utility values for different types of graft for ACL reconstruction. For patients in whom either an autograft or an allograft fails or who are in the conservative care arm, a utility value of 0.790 was assigned, which corresponded to the instability health state. For the few patients who get an infection, a disutility value for 6 weeks was applied. These utility values were then weighted by the length of time in that health state to estimate QALYs.

\section{Results}

Zeng et al. [52] reviewed systematic reviews and RCTs comparing allografts and autografts in people having primary ACL reconstruction. The review of reviews included ten systematic reviews and nine RCTs. The review was assessed as very high quality (eight of eight quality items rated as 'yes'). Autograft versus allograft (some of which used irradiated grafts) had a pooled risk ratio on the overall International Knee Documentation Committee (IKDC) level "normal and nearly normal' of 1.03 (95\% CI 1.00, 1.07); $p=0.03$, in favour of autograft. There was no statistical heterogeneity 


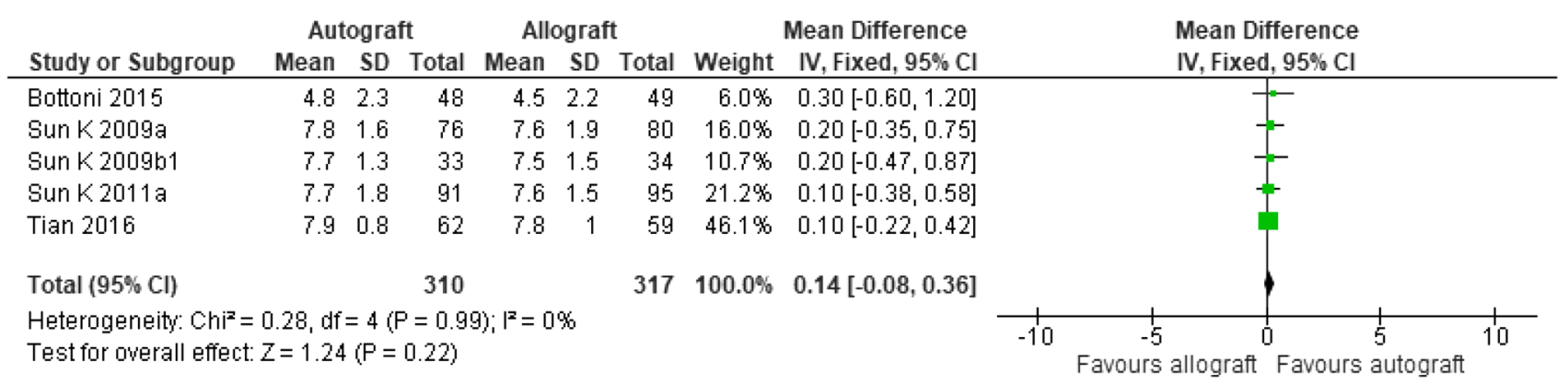

Fig. 1 Updated meta-analysis of non-irradiated allografts versus autografts, Tegner score

$\left(I^{2} 0 \%\right)$. However, when two studies were excluded in sensitivity analyses (the review examined single-study influence on results by removing one at a time) the pooled RR was no longer statistically significant. Clinical failure was also less frequent (RR, $0.47 ; 95 \%$ CI $0.31,0.73 ; p=0.0007 ; I^{2}$ $23 \%$ ), and Tegner scores (WMD, 0.36; 95\% CI 0.11, 0.60; $p=0.004 ; I^{2} 0 \%$ ) differences were also statistically significant, but the Lysholm score was not (weighted mean difference, WMD, 0.02; 95\% CI - 0.71, 0.75; non-significant (n.s.); $I^{2} 44 \%$ ). These analyses included studies using irradiated allografts. Subgroup analyses of autograft versus nonirradiated allografts were also reported for these outcomes, none of which were statistically significant (Lysholm WMD, -0.64 ; $95 \%$ CI - 1.45, 0.17; n.s.; $I^{2} 0 \%$; Tegner WMD 0.16; $95 \%$ CI $-0.16,0.47$; n.s.; $\left.I^{2} 0 \%\right)$. The authors concluded that autograft had advantages over irradiated allograft with respect to function and stability, whereas there were no significant differences between autograft and non-irradiated allografts.

Mariscalco et al [28] included nine studies comparing autografts with non-irradiated allografts, four of which were RCTs or mainly RCT (one trial had $25 \%$ patient choice and $75 \%$ randomised), with the other studies mainly patient choice. They found no difference in outcomes.

One review by Lording et al [25] did report a higher failure rate with non-irradiated allografts than with autografts, but the differences from previous reviews arose mainly from the inclusion of two studies, Bottoni et al. [4], and a study in people aged under 25 [22].

One of the primary studies, Gorschewski et al. [14] reported an unusually high failure rate with BPTB allografts, with failures in $21 \%$ at 2 years and $45 \%$ by 6 years in the allograft group, compared to $5 \%$ and $6 \%$ in the autograft group. The allografts were treated with the Tutoplast methods and were irradiated.

\section{Failure and revisions, allografts versus autografts}

Three of the primary studies reported failures and revision rates for allografts and autograft ACL reconstructions. In the RCT by Yoo et al. [51] at 33-35 months follow-up, the rates of revision were similar between groups (allografts $1.6 \%$; autografts $1.5 \%$ ). The rate of failure requiring revision was statistically significantly higher in the allograft group of the Bottoni et al. [4] RCT than the autograft group (26.5\% and $8.3 \%$, respectively, $p=0.03$, duration of followup 10.5 years). In the third study by Yang et al. [49], the failure rates at 2.5 years were $2.4 \%$ with allografts and $2.2 \%$ autograft. All three studies used fresh-frozen non-irradiated allografts.

The reasons for the higher failure rate in Bottoni et al. [4] are not clear. The operations were done a long time ago, perhaps at a time when processing methods were more damaging. Grafts came from a single tissue bank over a relatively short period of time.

Concerns has been expressed by some reviewers of a higher failure rate in allografts used in patients under the age of 25 [6]. Kane et al [22] found a higher revision rate in non-irradiated allograft BPTB grafts, but the potential for selection bias in that study was very high. In the large Kaiser Permanente database [26, 44], an increased rate of failure was noted for BPTB allografts compared to autografts which may explain the perceived differences. There was no statistical difference seen when autografts were compared to nonprocessed soft tissue allografts in the Kaiser Permanente series, although follow-up remains relatively short for this analysis [16].

\section{Clinical scores}

The Zeng meta-analysis [52] has been updated with the addition of some more recent studies as shown in Figs. 1 and 2.

\section{Adverse events}

Hardy et al [19] provide a systematic review specifically on the adverse events after harvesting autografts for ACL reconstruction. They note that in France most ACL reconstructions are done with autografts, taken from hamstring tendons, patellar tendon and fascia lata. They included 36 


\begin{tabular}{|c|c|c|c|c|c|c|c|c|c|c|}
\hline \multirow[b]{2}{*}{ Study or Subgroup } & \multicolumn{3}{|c|}{ Autograft } & \multicolumn{3}{|c|}{ Allograft } & \multirow[b]{2}{*}{ Weight } & \multirow{2}{*}{$\begin{array}{l}\text { Mean Difference } \\
\text { IV, Random, } 95 \% \mathrm{Cl}\end{array}$} & \multirow{2}{*}{$\begin{array}{c}\text { Mean Difference } \\
\text { IV, Random, 95\% Cl }\end{array}$} & \\
\hline & Mean & SD & Total & Mean & SD & Total & & & & \\
\hline Jia 2015 & 85.2 & 3.1 & 53 & 86.8 & 2.6 & 53 & $21.8 \%$ & $-1.60[-2.69,-0.51]$ & -- & \\
\hline Sun K 2009a & 90 & 8 & 76 & 91 & 6 & 80 & $11.2 \%$ & $-1.00[-3.23,1.23]$ & 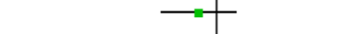 & \\
\hline Sun K 2009b1 & 90 & 9 & 33 & 91 & 8 & 34 & $4.5 \%$ & $-1.00[-5.08,3.08]$ & & \\
\hline $\operatorname{Sun} K 2011 \mathrm{a}$ & 89 & 9 & 91 & 90 & 8 & 95 & $9.9 \%$ & $-1.00[-3.45,1.45]$ & - & \\
\hline Sun R 2014 & 91.7 & 4.2 & 154 & 92.2 & 4 & 128 & $23.4 \%$ & $-0.50[-1.46,0.46]$ & - & \\
\hline Tian 2016 & 90 & 10 & 62 & 89 & 11 & 59 & $5.2 \%$ & $1.00[-2.75,4.75]$ & & \\
\hline Yang 2017 cohort & 91.8 & 2.8 & 90 & 90.9 & 3.3 & 85 & $24.0 \%$ & $0.90[-0.01,1.81]$ & $f=$ & \\
\hline Total $(95 \% \mathrm{Cl})$ & & & 559 & & & 534 & $100.0 \%$ & $-0.45[-1.39,0.48]$ & & \\
\hline $\begin{array}{l}\text { Heterogeneity: Tauz } \\
\text { Test for overall effect }\end{array}$ & $\begin{array}{l}0.73 ; \mathrm{C} \\
\mathrm{Z}=0.95\end{array}$ & $\begin{array}{l}\mathrm{i}^{2}= \\
(\mathrm{P}=\end{array}$ & $\begin{array}{l}13.59, \\
0.34)\end{array}$ & $\mathrm{df}=60$ & $=0$. & $03 ; i^{2}=$ & $56 \%$ & & \begin{tabular}{cc|cc}
1 & 1 & 1 & 1 \\
-10 & -5 & 0 & 5 \\
Favours allograft & Favours
\end{tabular} & $\begin{array}{l}10 \\
\text { tograft }\end{array}$ \\
\hline
\end{tabular}

Fig. 2 Updated meta-analysis of non-irradiated allografts versus autografts, Lysholm score

articles in a good-quality review. For hamstring autografts, they conclude that there are complications in $8.3 \%$ of cases (though some studies have much higher rates). The commonest is saphenous nerve damage, though they think this is largely avoidable by a different approach. Temporary strength deficits (up to 3 months) occur. Because these complications are temporary, they will have insignificant impact on the long-term economics.

They estimate fewer complications with patellar tendon (PT) grafts (0.2-1.2\% overall) but some more serious, including patellar fracture in $0.42-1.3 \%$, rupture of PT and anterior knee pain, reported in as many as $46 \%$, but with varying definitions.

To guide practice, an evidence review from New Zealand from Accident Compensation Corporation Research [39] has been produced. It was based on an overview of 12 systematic reviews. The primary studies were not examined. The last search was done in May 2016, and the reviews were published from 2007 to 2015. The ACC report concluded that there was no evidence of any significant differences in failure rates or other outcomes, between autografts and non-irradiated allografts. It concluded that allografts irradiated with low doses still performed less well than non-irradiated allografts, and that low doses were not sufficient to eliminate the risk of disease transmission. Given the similar outcomes, cost became the determining factor. It appears that costs of allografts are higher in NZ than elsewhere because there is no local provider.

Older studies may not reflect modern processing methods. Fresh-frozen allografts give better results. MardaniKivi et al. [27] found no difference in outcomes between fresh-frozen tibialis posterior allografts and hamstring autografts after 55 months. Krych et al. [23] reported a meta-analysis showing that BPTB autografts did better than allografts, but the advantage only applied when allografts were irradiated or chemically processed.

\section{Cost-effectiveness}

\section{Previous studies}

Salzmann et al. [38] provide a review of 24 economic studies in ACL reconstruction (ACLR). They note that 17 were reports only of costs, of which five compared autograft and allograft ACLR. The other seven include three cost-utility studies of ACLR versus non-operative management, with all three concluding that surgery was more cost effective. Two studies compared the cost-effectiveness of single versus double-bundle techniques. One study compared prompt versus delayed ACLR. The remaining study by Genuario et al. [13] was the one most relevant to this review, because it compared autografts with allografts. They found that hamstring autograft was least costly and more effective, than both BPTB and allograft reconstructions.

Some studies report small differences in in-patient stays. Gorschewski et al. [14] reported mean stays of 5.2 days for allografts and 6.3 days for autografts. They also reported a slightly earlier return to work after allografts (2.3 months versus 2.6 months, $p=0.004$ ).

Cooper and Kaeding [9] report hospital costs for ACL reconstruction of $\$ 4,072$ for autografts and $\$ 5,195$ for allografts. The slightly shorter theatre time for allografts had little effect on the cost differential.

Oro et al. [35] also report that operating time was 12 min longer with autograft but the total cost was about $\$ 1000$ more with allograft.

Cohen et al. [7] report that saphenous nerve damage is commoner after ACLR with autografts, but not enough to be economically significant.

Greis et al. [18] compare costs of tibialis allografts with hamstring autografts in Utah. The mean cost of ACLR allografting was $\$ 4587$ with theatre time of $92 \mathrm{~min}$. The autograft cost was $\$ 3489$ with 125 min of theatre time. 
Cole et al. [8] report hospital charges of $\$ 4622$ for allografts and $\$ 5694$ for autografts. The difference is due to longer operating theatre time and longer inpatient stays for autograft patients.

One issue to be considered in interpretation of all costeffectiveness studies is how old the clinical effectiveness data that support them are. For example, older studies may have a mixture of allografts sterilised by different methods, including radiation. The high-quality review by Zeng et al. [52] showed no difference in success rates when allografts were compared with non-irradiated grafts, but that autografts were more successful than irradiated grafts.

\section{Modelling}

Table 3 shows the base-case deterministic results.

Having an allograft as a primary ACL reconstruction is more costly ( $£ 2,426$ more) and no more effective (very slightly less effective at 0.0026 QALYs-though this is not clinically significant) than having a HS autograft as a primary ACL reconstruction: that is, HS autografts "dominated" allografts. The main cost driver for this result was the cost of the graft. The second but less important factor was that the failure rate for allograft was slightly higher, by $1.3 \%$ (6.9\% versus $5.6 \%$ ) than the HS autograft. However, this has little impact compared to allograft cost.

There are some small advantages for allografts—slightly shorter theatre time, no donor site morbidity-but these factors are too small to significantly affect cost-effectiveness.

\section{Discussion}

When there are existing good-quality reviews, it is unnecessary and indeed wasteful to repeat them. They should simply be updated with any new trials, as has been done in this article. There have been numerous reviews and RCTs in this area, mostly with consistent results. Where there are differences in the failure rates of ACL reconstructions between allografts and autografts, these can mostly be explained by the use of irradiated grafts. Giving sufficient radiation to achieve sterility will likely weaken grafts and make them more likely to fail and, therefore, the practice of irradiating grafts is not recommended.
The evidence shows no significant differences in clinical effectiveness between autografts and non-irradiated allografts. Failure rates with both grafts are now low. BPTB allografts have been described as having higher failure rates in some studies, compared to autograft, but this does not seem to be the case for soft tissue allografts, with only one RCT showing a difference between soft tissue allograft and autografts [4], whilst the majority of RCTs had failure rates that were very similar. The RCT by Bottoni et al [4] that showed a difference had an unusually high allograft failure rate of $27 \%$. The reasons for this are not clear. The operations were done a long time ago, perhaps at a time when processing methods were more damaging. Grafts came from a single tissue bank over a relatively short period of time.

Failure does not necessarily mean that there was something wrong with the procedure or the technology. It should be borne in mind that people having these procedures do so because they have damaged or ruptured their own tissues, perhaps by putting great demands on the knee structures, often during sport.

When an intervention has a higher cost than the comparator, but is no more clinically effective, or less effective, it is said to be "dominated" in cost-effectiveness analysis as is the case with allografts in this study. Costs with allografts are higher because of the cost of the graft, and the cost we used may be less than that in other countries. The findings of the economic modelling need to take into account the local costs of the graft, but this can be done simply based on the data shown here, as the cost of the graft was the dominant factor in the economic model.

There is less morbidity with allografts because they are not harvested from the live patient, but the disutility is transient and insufficient to change the overall conclusion on cost-effectiveness. Hardy et al [19] specifically conducted a review on the adverse events after harvesting autografts for ACL reconstruction. For hamstring autografts, they conclude that there are complications in $8.3 \%$ of cases, the commonest is saphenous nerve damage. Temporary strength deficits (up to 3 months) occur. Because these complications are temporary, they will have insignificant impact on the long-term economics [19].

Revision ACL reconstruction is also an effective operation, using the hamstring or BPTB graft from either the same leg or the other leg. This study was not directly designed to compare allograft and autograft usage for revision ACL
Table 3 Base-case deterministic discounted results, ACL reconstruction

\begin{tabular}{llllll}
\hline Procedure & $\begin{array}{l}\text { Total mean } \\
\text { costs } £\end{array}$ & $\begin{array}{l}\text { Total mean } \\
\text { QALYs }\end{array}$ & Incremental costs & Incremental QALYs & ICER \\
\hline HS autograft & $£ 2420$ & 2.6980 & - & - & - \\
Allograft & $£ 4846$ & 2.6953 & $£ 2426$ & -0.0026 & Dominated \\
\hline
\end{tabular}

$I C E R$ incremental cost-effectiveness ratio 
reconstruction, but a review of the literature shows no difference in failure rate between allograft and autograft revision ACL reconstruction and, therefore, the cost of the allograft will continue to dominate the economic analysis.

There may be situations in which allografts should be considered. The review has assumed that a direct choice can be made between allografts and autografts, and that both are available. There may be situations where a satisfactory autograft is not available, for example in multi-ligament injury where available autografts will be used for other reconstructions. Also, in the setting of revision ACL reconstruction, there are various considerations regarding graft choice, due to tunnel size or position, previous usage of other grafts, and reconstructions in the other leg, that may mean that allografts would be preferred to autografts. The other population not covered sufficiently in the literature for us to draw conclusions is the elite sprinting athlete where autograft choices may be influenced by the effect of graft harvesting on their sport. However, in the majority of cases, it may be concluded that allograft ACL reconstruction with non-irradiated grafts is as safe, but more expensive then autograft ACL reconstruction, which is preferred as it is more cost effective.

\section{Conclusion}

There is little difference in results of ACL reconstruction with autografts or non-irradiated allografts, with any advantage being with autografts. The cost is higher with allografts. So if autografts are available, allografts are not cost effective.

Acknowledgements We thank ESSKA for funding the full report on allografts, from which this article is derived. We thank Tim Spalding, Laura di Girolamo and Peter Verdonk for comments on the ESSKA report, and those who attended the ESSKA workshop on allografts in May 2018 for useful discussions.

Author contributions PR carried out literature searches, and PR and NW filtered the retrieved studies. EL and JC carried out quality assessment of clinical effectiveness studies and extracted and summarised data. HM carried out the cost analysis. AM and NAS provided clinical expertise and commentary. NW and PR collated the drafts. All authors contributed comments and edits to the final report.

Funding Funding was provided by European Society of Sport Traumatology, Knee Surgery and Arthroscopy (ESSKA).

\section{Compliance with ethical standards}

Conflict of interest The authors declare that they have no potential conflict of interest.

Ethical approval This systematic review and economic analysis did not involve primary data collection from patients and as such research approval was not obtained.
Open Access This article is distributed under the terms of the Creative Commons Attribution 4.0 International License (http://creativeco mmons.org/licenses/by/4.0/), which permits unrestricted use, distribution, and reproduction in any medium, provided you give appropriate credit to the original author(s) and the source, provide a link to the Creative Commons license, and indicate if changes were made.

\section{References}

1. Ara R, Brazier JE (2010) Populating an economic model with health state utility values: moving toward better practice. Value Health 13:509-518

2. Bansal A, Lamplot JD, Vandenberg J, Brophy RH (2017) Metaanalysis of the risk of infections after anterior cruciate ligament reconstruction by graft type. Am J Sports Med 46:1500-1508

3. Barker JU, Drakos MC, Maak TG, Warren RF, Williams RJ 3rd, Allen AA (2010) Effect of graft selection on the incidence of postoperative infection in anterior cruciate ligament reconstruction. Am J Sports Med 38:281-286

4. Bottoni CR, Smith EL, Shaha J, Shaha SS, Raybin SG, Tokish JM et al (2015) Autograft versus allograft anterior cruciate ligament reconstruction: a prospective, randomized clinical study with a minimum 10-year follow-up. Am J Sports Med 43:2501-2509

5. British Medical Association, Royal Pharmaceutical Society of Great Britain (2017) British national formulary no. 72, September 2016-March 2017. BMA and PRS, London

6. Brown MJ, Carter T (2018) ACL allograft: advantages and when to use. Sports Med Arthrosc Rev 26:75-78

7. Cohen SB, Flato R, Wascher J, Watson R, Salminen M, O'Brien $\mathrm{D}$ et al (2018) Incidence and characterization of hypoesthesia in the distribution of the infrapatellar branch of the saphenous nerve after anterior cruciate ligament reconstruction: a prospective study of patient-reported numbness. J Knee Surg 31:585-590

8. Cole DW, Ginn TA, Chen GJ, Smith BP, Curl WW, Martin DF et al (2005) Cost comparison of anterior cruciate ligament reconstruction: autograft versus allograft. Arthroscopy 21:786-790

9. Cooper MT, Kaeding C (2010) Comparison of the hospital cost of autograft versus allograft soft-tissue anterior cruciate ligament reconstructions. Arthroscopy 26:1478-1482

10. Curtis L, Burns A (2017) Personal social services research unit university of kent. Unit Costs of Health and Social Care. https:// kar.kent.ac.uk/65559/. Accessed 25 Nov 2018

11. Curtis L, Burns A (2016) Personal social services research unit university of kent. Unit Costs of Health and Social Care 2016. https://www.pssru.ac.uk/project-pages/unit-costs/unit-costs-2016/. Accessed 25 Nov 2018

12. Cvetanovich GL, Mascarenhas R, Saccomanno MF, Verma NN, Cole BJ, Bush-Joseph CA et al (2014) Hamstring autograft versus soft-tissue allograft in anterior cruciate ligament reconstruction: a systematic review and meta-analysis of randomized controlled trials. Arthroscopy 30:1616-1624

13. Genuario JW, Faucett SC, Boublik M, Schlegel TF (2012) A costeffectiveness analysis comparing 3 anterior cruciate ligament graft types: bone-patellar tendon-bone autograft, hamstring autograft, and allograft. Am J Sports Med 40:307-314

14. Gorschewsky O, Klakow A, Riechert K, Pitzl M, Becker R (2005) Clinical comparison of the tutoplast allograft and autologous patellar tendon (bone-patellar tendon-bone) for the reconstruction of the anterior cruciate ligament-2-and 6-year results. Am J Sports Med 33:1202-1209

15. GOV.UK. NHS reference costs 2015 to 2016. 2016. https://www. gov.uk/government/publications/nhs-reference-costs-2015-to2016. Accessed 25 Nov 2018 
16. Gracitelli GC, Moraes VY, Franciozi CES, Luzo MV, Belloti JC (2016) Surgical interventions (microfracture, drilling, mosaicplasty, and allograft transplantation) for treating isolated cartilage defects of the knee in adults. Cochrane Database Syst Rev 2016:9

17. Grassi A, Nitri M, Moulton SG, Marcheggiani Muccioli GM, Bondi A, Romagnoli M et al (2017) Does the type of graft affect the outcome of revision anterior cruciate ligament reconstruction? a meta-analysis of 32 studies. Bone Joint J 99-B:714-723

18. Greis PE, Koch BS, Adams B (2012) Tibialis anterior or posterior allograft anterior cruciate ligament reconstruction versus hamstring autograft reconstruction: an economic analysis in a hospital-based outpatient setting. Arthroscopy 28:1695-1701

19. Hardy A, Casabianca L, Andrieu K, Baverel L, Noailles T (2017) Complications following harvesting of patellar tendon or hamstring tendon grafts for anterior cruciate ligament reconstruction: systematic review of literature. Orthop Traumatol Surg Res 103:S245-Ss248

20. Hulet C, Sonnery-Cottet B, Stevenson C, Samuelsson K, Laver L, Zdanowicz U et al (2018) The use of allograft tendons in primary ACL reconstruction: a narrative review of the clinical evidence (personal communication)

21. Kan SL, Yuan ZF, Ning GZ, Yang B, Li HL, Sun JC et al (2016) Autograft versus allograft in anterior cruciate ligament reconstruction: a meta-analysis with trial sequential analysis. Medicine 95:e4936

22. Kane PW, Wascher J, Dodson CC, Hammoud S, Cohen SB, Ciccotti MG (2016) Anterior cruciate ligament reconstruction with bone-patellar tendon-bone autograft versus allograft in skeletally mature patients aged 25 years or younger. Knee Surg Sports Traumatol Arthrosc 24:3627-3633

23. Krych AJ, Jackson JD, Hoskin TL, Dahm DL (2008) A metaanalysis of patellar tendon autograft versus patellar tendon allograft in anterior cruciate ligament reconstruction. Arthroscopy 24:292-298

24. Lawhorn KW, Howell SM, Traina SM, Gottlieb JE, Meade TD, Freedberg HI (2012) The effect of graft tissue on anterior cruciate ligament outcomes: a multicenter, prospective, randomized controlled trial comparing autograft hamstrings with fresh-frozen anterior tibialis allograft. Arthroscopy 28:1079-1086

25. Lording T, Steiner J, Hewison C, Neyret P, Lustig S (2017) Autograft superior to both irradiated and non-irradiated allograft for primary ACL reconstruction: a systematic review. JISAKOS 2:247-259

26. Maletis GB, Chen J, Inacio MCS, Love RM, Funahashi TT (2017) Increased risk of revision after anterior cruciate ligament reconstruction with bone-patellar tendon-bone allografts compared with autografts. Am J Sports Med 45:1333-1340

27. Mardani-Kivi M, Karimi-Mobarakeh M, Keyhani S, Saheb-Ekhtiari K, Hashemi-Motlagh K, Sarvi A (2016) Hamstring tendon autograft versus fresh-frozen tibialis posterior allograft in primary arthroscopic anterior cruciate ligament reconstruction: a retrospective cohort study with three to six years follow-up. Int Orthop 40:1905-1911

28. Mariscalco MW, Magnussen RA, Mehta D, Hewett TE, Flanigan DC, Kaeding CC (2014) Autograft versus nonirradiated allograft tissue for anterior cruciate ligament reconstruction: a systematic review. Am J Sports Med 42:492-499

29. Mascarenhas R, Erickson BJ, Sayegh ET, Verma NN, Cole BJ, Bush-Joseph C et al (2015) Is there a higher failure rate of allografts compared with autografts in anterior cruciate ligament reconstruction: a systematic review of overlapping meta-analyses. Arthroscopy 31:364-372

30. Mohan R, Webster KE, Johnson NR, Stuart MJ, Hewett TE, Krych AJ (2018) Clinical outcomes in revision anterior cruciate ligament reconstruction: a meta-analysis. Arthroscopy 34:289-300
31. National Institute for Health and Care Excellence. Assessing cost effectiveness -guidelines manual. 2012. https://www.nice.org. uk/process/pmg6/chapter/assessing-cost-effectiveness. Accessed 1 May 2012

32. NHS Blood and Transplant. Tissue and Eye Services. 2018. http:// www.nhsbt.nhs.uk/tissue-and-eye-services/products/. Accessed 3 Dec 2018

33. Noh JH, Yi SR, Song SJ, Kim SW, Kim W (2011) Comparison between hamstring autograft and free tendon Achilles allograft: minimum 2-year follow-up after anterior cruciate ligament reconstruction using EndoButton and Intrafix. Knee Surg Sports Traumatol Arthrosc 19:816-822

34. OECD. Purchasing power parities (PPP) (indicator). 2018. https ://data.oecd.org/conversion/purchasing-power-parities-ppp.htm. Accessed 3 Dec 2018

35. Oro FB, Sikka RS, Wolters B, Graver R, Boyd JL, Nelson B et al (2011) Autograft versus allograft: an economic cost comparison of anterior cruciate ligament reconstruction. Arthroscopy 27:1219-1225

36. Park SS, Dwyer T, Congiusta F, Whelan DB, Theodoropoulos J (2015) Analysis of irradiation on the clinical effectiveness of allogenic tissue when used for primary anterior cruciate ligament reconstruction. Am J Sports Med 43:226-235

37. Prentice HA, Lind M, Mouton C, Persson A, Magnusson H, Gabr A et al (2018) Patient demographic and surgical characteristics in anterior cruciate ligament reconstruction: a description of registries from six countries. Br J Sports Med 52:716-722

38. Saltzman BM, Cvetanovich GL, Nwachukwu BU, Mall NA, BushJoseph CA, Bach BR Jr (2016) Economic analyses in anterior cruciate ligament reconstruction: a qualitative and systematic review. Am J Sports Med 44:1329-1335

39. Stephenson M. Allograft for use in primary anterior cruciate ligament reconstruction: evidence-based review. 2016. https://www. acc.co.nz/assets/research/allograft-review.pdf. Accessed $27 \mathrm{Sept}$ 2017

40. Stewart BA, Momaya AM, Silverstein MD, Lintner D (2017) The cost-effectiveness of anterior cruciate ligament reconstruction in competitive athletes. Am J Sports Med 45:23-33

41. Sun K, Tian S, Zhang J, Xia C, Zhang C, Yu T (2009) Anterior cruciate ligament reconstruction with BPTB autograft, irradiated versus non-irradiated allograft: a prospective randomized clinical study. Knee Surg Sports Traumatol Arthrosc 17:464-474

42. Sun K, Tian SQ, Zhang JH, Xia CS, Zhang CL, Yu TB (2009) Anterior cruciate ligament reconstruction with bone-patellar tendon-bone autograft versus allograft. Arthroscopy 25:750-759

43. Sun K, Zhang J, Wang Y, Xia C, Zhang C, Yu T et al (2011) Arthroscopic anterior cruciate ligament reconstruction with at least 2.5 years' follow-up comparing hamstring tendon autograft and irradiated allograft. Arthroscopy 27:1195-1202

44. Tejwani SG, Chen J, Funahashi TT, Love R, Maletis GB (2015) Revision risk after allograft anterior cruciate ligament reconstruction: association with graft processing techniques, patient characteristics, and graft type. Am J Sports Med 43:2696-2705

45. Wasserstein D, Sheth U, Cabrera A, Spindler KP (2015) A systematic review of failed anterior cruciate ligament reconstruction with autograft compared with allograft in young patients. Sports Health 7:207-216

46. Waterman BR, Arroyo W, Cotter EJ, Zacchilli MA, Garcia EJ, Owens BD (2018) Septic arthritis after anterior cruciate ligament reconstruction: clinical and functional outcomes based on graft retention or removal. Orthop J Sports Med 6:1-6. https://doi. org/10.1177/2325967118758626

47. Wei J, Yang HB, Qin JB, Yang TB (2015) A meta-analysis of anterior cruciate ligament reconstruction with autograft compared with nonirradiated allograft. Knee 22:372-379 
48. World Bank. GDP deflator. 2016. https://data.worldbank.org/indic ator/NY.GDP.DEFL.ZS. Accessed 3 Dec 2018

49. Yang R, Deng H, Hou J, Ouyang Y, Chen Z, Song B et al (2017) Comparison of knee stability and synovial fluid alterations in anterior cruciate ligament reconstruction with a hamstring autograft or an allograft. Orthopedics 40:e892-e897

50. Yao LW, Wang Q, Zhang L, Zhang C, Zhang B, Zhang YJ et al (2015) Patellar tendon autograft versus patellar tendon allograft in anterior cruciate ligament reconstruction: a systematic review and meta-analysis. Eur J Orthop Surg Traumatol 25:355-365

51. Yoo SH, Song EK, Shin YR, Kim SK, Seon JK (2017) Comparison of clinical outcomes and second-look arthroscopic findings after ACL reconstruction using a hamstring autograft or a tibialis allograft. Knee Surg Sports Traumatol Arthrosc 25:1290-1297
52. Zeng C, Gao SG, Li H, Yang T, Luo W, Li YS et al (2016) Autograft versus allograft in anterior cruciate ligament reconstruction: a meta-analysis of randomized controlled trials and systematic review of overlapping systematic reviews. Arthroscopy 32:153163.e118

Publisher's Note Springer Nature remains neutral with regard to jurisdictional claims in published maps and institutional affiliations. 